\title{
A “janela da expressão": reflexões sobre corpo, movimento e gesto nas relações entre visão e cegueira
}

The "window of expression": reflections about body, movement and gesture in the relations between vision and blindness

\section{Olivia von der Weid}

\section{QpenEdition Journals}

\section{Edição electrónica}

URL: http://journals.openedition.org/aa/3506

DOI: $10.4000 /$ aa. 3506

ISSN: 2357-738X

\section{Editora}

Programa de Pós-Graduação em Antropologia Social (UnB)

\section{Edição impressa}

Data de publição: 1 junho 2019

Paginação: 159-186

ISSN: 0102-4302

\section{Refêrencia eletrónica}

Olivia von der Weid, "A "janela da expressão": reflexões sobre corpo, movimento e gesto nas relações entre visão e cegueira», Anuário Antropológico [Online], v.44 n. 1 | 2019, posto online no dia 06 julho 2019, consultado o 28 abril 2021. URL: http://journals.openedition.org/aa/3506 ; DOI: https://doi.org/ $10.4000 /$ aa.3506

\section{@(@) $\Theta \Theta$}

Anuário Antropológico is licensed under a Creative Commons Atribuição-Uso Não-Comercial-Proibição de realização de Obras Derivadas 4.0 International. 


\title{
A “janela da expressão": reflexões sobre corpo, movimento e gesto nas relações entre visão e cegueira
}

\author{
Olivia von der Weid \\ Universidade Federal Fluminense - Brasil
}

Eu acho que tem uma coisa que é muito maior para nós, cegos, nesse trabalho... o mundo é um lugar onde você está sendo visto. Na verdade, o mundo é um grande teatro né? (...) nessas últimas experiências eu fui ficando menos ingênua e me dando conta.

E isso me marcou.

Não é a forma de entender, porque não é uma mudança intelectual. Muda a forma de estar no mundo. Abriu a janela da expressão.

(Dora)

A primeira vez em que estive com Dora para uma conversa mais prolongada em sua casa provocou sensações de estranhamento que talvez possam ser associadas àqueles momentos da pesquisa de explosão de significados, em que cada fato observado na cultura nativa tem significado para o pesquisador (Malinowski, 1986). Enquanto conversávamos, ia me dando conta, de uma forma até então inédita para mim, do meu próprio corpo no ato de conversar. Gesticulo enquanto conto uma história ou revelo algo do meu pensamento. Como se tais movimentos ajudassem a expressar o que digo, mesmo que naquela conversa também parecessem inúteis. Percebo a necessidade de completar todas as frases, as insinuações gestuais de nada servem. Assim como não comunicam expressões como "lá", "ali", "ele”, ou o ato de apontar ou demonstrar fisicamente alguma coisa.

Dirijo o olhar para os olhos dela, ainda que sejam olhos com movimento, mas sem retorno. Presto atenção na entonação da voz, como se despendesse um esforço maior em expressar sonoramente as mudanças de estado na conversa. A própria fala surge com uma urgência, uma ascendência maior nesse encontro e os silêncios vibram mais enigmáticos quando não se tem a cumplicidade do olhar. O corpo inteiro precisa ser através do que digo, expressar o que sinto ou penso pela impos- 
tação e variação da voz. Uma aparente invisibilidade promove o sobressalto tanto da fala quanto da própria expressividade corporal, como se a ausência do seu olhar voltasse o foco a mim mesma.

A interação e o convívio com olhos que não veem me colocam em contato com a própria corporalidade, densidade carnal em ação no ato de comunicar. A ausência de seu olhar derrama luz sobre meus gestos, a fala, a postura, o fluxo dos movimentos, a direção de meus olhos. O corpo, para Merleau-Ponty (1971), é um "sensível exemplar” porque sensível para si - se sente ao sentir que sente. O invisível dos olhos de Dora torna visível a mim, ao corpo de alguém que percebe a si mesma, vendo.

O estranhamento posteriormente suscitou reflexões sobre o destaque que se dá à linguagem verbal e à funcionalidade corporal na educação e/ou reabilitação de pessoas cegas, e uma espécie de lacuna que senti naquela conversa. É claro que pude me fazer entender e compreendia suas colocações, a lacuna não estava no que era dito, mas nos gestos. Não podiam se transformar em recursos visuais explícitos de comunicação, mesmo que implicitamente pudessem e fossem utilizados como uma espécie de auxílio, um adicional de ênfase na fala, ajudando a fazer variar a tonalidade e a cadência do que era dito.

Neste artigo proponho considerar os meios não discursivos que medeiam a relação entre expressividade e comunicação entre pessoas cegas e não cegas. Quais as implicações advindas de uma interação que se baseia na dupla condição de ver e não ser visto/não ver e ser visto? Qual o papel dos movimentos e dos gestos nessa experiência comunicativa? Falar em gesto é uma tentativa de trazer para a reflexão não apenas o aspecto prático ou funcional da ação, mas também suas dimensões corporais e afetivas, sua poética e plasticidade (Silva, 2016).

A percepção de mundo de pessoas cegas se constrói nas brechas de uma dupla fronteira: uma limitação física e um impedimento social. Com a ausência da visão, os outros sentidos e o corpo inteiro se colocam como mecanismos de apreensão do mundo, do espaço e das pessoas, mas na vida cotidiana, o conhecimento pelo tato esbarra na restrição social ao toque entre pessoas (Le Breton, 2011). A reflexão desenvolvida se localiza na fronteira entre um conhecimento tátil do mundo por um corpo privado da visão e as barreiras sociais para o conhecimento corporal do outro através do tato.

A restrição social ao toque traz implicações para a apreensão, por pessoas cegas, de uma linguagem corporal comunicativa presente nos gestos, seja como forma 
de conhecimento da cultura, seja como recurso expressivo nas relações de interação. Abordo as consequências desse hiato a partir das possibilidades criativas que se abrem para o resgate e a construção desta linguagem corporal por intermédio da arte, a partir da participação, como parte do trabalho de campo, em oficinas de teatro com pessoas cegas e não cegas ${ }^{1}$. O engajamento nessas experiências colocou desafios importantes e levantou questões sobre as potencialidades dos dispositivos propositivos de pesquisa para a investigação antropológica que desenvolvi em outro lugar (von der Weid, 2017). A análise aqui elaborada se volta especialmente para a interlocução desenvolvida com Dora ${ }^{2}$, a partir dos questionamentos suscitados por suas vivências anteriores em oficinas teatrais e pelas experiências que partilhamos na Oficina Inclusiva.

Como sugeriu Hammer (2013), realizar uma etnografia da cegueira levanta complexidades específicas resultantes das relações desequilibradas de poder em torno do olhar do pesquisador. A pesquisa exige que se desenvolva uma sensibilidade sensorial alternativa capaz de desafiar a associação comum do conhecimento com a visão e o olhar. Um segundo aspecto decorrente da relação entre visão e cegueira a partir de uma etnografia em que a pesquisadora enxerga e os pesquisados não, é o efeito de intensificação da consciência para certas propriedades das interações sociais que normalmente poderiam passar despercebidas. Neste artigo enfatizo, sobretudo, a dimensão da corporalidade na comunicação, com especial atenção ao movimento, aos gestos e à expressividade.

\section{Silêncios e ruídos: suspensões da comunicação}

Trato inicialmente as interações entre pessoas cegas e pessoas que enxergam como "ocasiões situadas", pensando-as a partir da abordagem interacionista de Goffman $(1966,2011)$. Encontros onde existe a copresença de outros e em que grande parte das informações veiculadas depende não só daquilo que é falado, mas da atividade corporal dos agentes. O autor destaca o papel organizador do olhar na vida social comunicativa, o que ajuda a entender o estranhamento inicial na conversa com Dora em sua casa. Em encontro posterior, ela reconhece que uma das possíveis dificuldades das pessoas que enxergam na relação com a cegueira está vinculada à falta da visualidade na conversa:

Às vezes as pessoas têm dificuldade de lidar com uma pessoa cega pela dificuldade de comunicação. Porque como não rola o olho no olho, as pessoas ficam meio 
perdidas e elas não conseguem ver se elas estão sendo ouvidas, se elas estão sendo entendidas... sabe, eu acho que rola essa agonia nas pessoas, essa dificuldade assim em um primeiro momento.

Goffman (2011) identifica que, nas interações faladas, um sistema de práticas, convenções e regras de procedimentos entra em jogo, funcionando como um meio para orientar e organizar a troca de mensagens. Os receptores, através de gestos apropriados, comunicam ao orador que estão dando a ele a sua atenção. A visualidade organiza o fluxo da fala em uma interação. A função organizadora do olhar é também destacada por Le Breton (2009), quando diz que os olhos, ao receberem e simultaneamente transmitirem informações, concorrem para o desenrolar de uma conversa. O próprio contato ocular dá aos indivíduos o sentimento de estar em interação. Em uma "ocasião social” em que um indivíduo se apresenta diante de outros, o silêncio pode parecer enigmático para uma pessoa cega.

Eu me lembro de um treinamento que fui dar para um pessoal em Florianópolis. Eu comecei a falar e um silêncio absoluto (na plateia). E eu falava e aquele silêncio absoluto. Aquilo foi me dando uma agonia, porque eu ficava pensando "meu Deus, será que esse povo está dormindo? Tão bocejando? Tão achando esse negócio muito chato? Tô chovendo no molhado, eles já sabem isso? Ou eu estou falando muito difícil e eles não estão entendendo? O que está acontecendo?”A té que alguém falou assim “olha, quando quiser fazer o coffee break...”, eu digo, “opa, então pessoal, vamos dar um pequeno intervalo para a gente tomar um café e depois continuamos". Aí cheguei pros meus colegas e disse "gente, o quê que é isso? Por que esse silêncio? Esse povo está dormindo?" e aí as pessoas disseram para mim “não, eles estão anotando. Tudo o que você está falando eles estão anotando no verso da apostila que você deu. Eles estão ouvindo tudo, prestando atenção e anotando”. Eles estavam alucinados, copiando tudo e eu achando que o povo estava dormindo, tava entediado... Por quê? Aqui no Rio as pessoas até podiam estar copiando, mas o carioca copia e fala. Não é? O pessoal do Sul é menos falante, mais quieto, é mais disciplinado. Então eu estava sentindo dois choques, tinha o choque de eu não estar vendo e tinha o choque cultural, de não estar com o povo da minha cidade. O treinamento aqui no Rio eu tinha que pedir silêncio de $5 \mathrm{em} 5$ minutos e lá eu tinha que pedir "falem, por favor", tinha que pedir retorno (Dora).

No universo perceptivo da cegueira, as pessoas entram ou saem da invisibilidade por seu silêncio ou sua sonoridade. Essa é uma das características que Hull (1997) atribui ao espaço acústico, de natureza efêmera, cujos habitantes transitam dentro e 
fora da existência pelos ruídos que emitem. No caso trazido por Dora, não é apenas o silêncio em si que perturba o fluxo da interação, mas o contexto cultural também influencia na sua percepção da cena. Por não estar em sua cidade, onde consegue perceber os sinais pelo comportamento rumoroso das pessoas, Dora teve maior dificuldade em se orientar pela conduta da plateia e codificar o seu silêncio.

Le Breton (2009) fala da comunicação em ambientes rumorosos, em que a qualidade da conversa pode ser mantida pela focalização visual. Quando é assim, muitas pessoas conversando, Dora acha mais difícil acompanhar:

Numa situação que está só você e uma pessoa é mais fácil, não interessa o primeiro contato, você está mais no controle. Agora numa situação que são várias pessoas é meio complicado você ter certeza que a pessoa te ouviu, porque tem outras pessoas falando ao mesmo tempo. Você ter certeza que a pessoa te ouviu e você ter certeza que o outro está falando é com você mesmo ou se é com o outro que está do seu lado. (...) Eu sinto que tem uma questão do contato visual que facilita a comunicação. Se eu estou olhando para você, se eu posso ver o seu rosto, se eu posso ver principalmente os seus olhos eu estou sabendo se você está prestando atenção no que eu estou falando. Ou se eu não estou falando com você, eu estou sabendo se eu posso falar agora, se você vai prestar atenção no que eu vou falar. E quando você não tem isso fica complicado. A pessoa que não enxerga não sabe se pode falar e a pessoa que enxerga não sabe se o cego está falando com ele, ou com quem que o cego está falando. Então fica um ruído de comunicação.

Le Breton (2009) destaca que o olhar orienta a troca de enunciados em uma conversação, funcionando como apoio para os atores, que buscam o assentimento do olhar alheio para suas reflexões ou investigam o momento propício de entrar em uma conversa ou de tomar a palavra. Nessas situações, Dora se sente em desvantagem por não poder usufruir de tal código. É comum acontecer em ambientes com mais gente, com conversas paralelas. Mas também pode acontecer em um encontro face a face quando a outra pessoa, temporariamente, esquece que ela é cega e por isso esquece de avisá-la, por exemplo, que vai atender ao telefone celular:

Eu digo: - “o quê, fulano? O que você está perguntando? Eu vou onde?”. E fulano está falando no telefone, mas eu não percebi que o telefone tocou, estava no vribracall, entendeu? Ou então eu não tava nem perto, não estou nem prestando atenção, mas a pessoa começou a falar e aí eu comecei a achar que era comigo. 
Para Mitchell (2010), o gesto tem a função comunicativa de enquadrar a ação e organizá-la em termos de importância. Ele também pode interromper o discurso e pode interromper as próprias ações, precisamente para reordenar a relação entre palavras e feitos, palavras e coisas. No caso mencionado, o gesto de atender o celular e com isso, sinalizar a interrupção de uma conversa. Nós não apenas fazemos coisas com as mãos ou com a face, mas dizemos coisas com elas. Coisas que nem sempre confirmam o que estamos dizendo verbalmente com as palavras. Silva (2016) identifica aí o potencial ambivalente do gesto, capaz de suspender o movimento, que se desenvolve sobre movimentos, expressando aquilo que importa em uma ação. $\mathrm{O}$ gesto faz e diz, mas às vezes diz justamente ao não fazer, ao interromper ou suspender um movimento.

A reflexão nos coloca diante de situações que envolvem a cegueira, as expectativas sociais de conduta e as possíveis técnicas e estratégias desenvolvidas por pessoas cegas e seu "coletivo" (manuais de desenvolvimento e educação de crianças cegas, profissionais dos programas de reabilitação, materiais utilizados nesses ambientes, etc.) para cumprir as convenções sociais em uma interação de tipo pública.

\section{Gestos sociais e estratégias corporais na interação}

O conjunto particular de regras que transformam um indivíduo em um membro da sociedade deriva de requerimentos estabelecidos na organização ritual dos encontros sociais (Goffman, 2011). Em ocasiões desse tipo, qualquer pessoa manifestará a preocupação de adotar uma conduta socialmente aceitável. Como vimos, a falta da visão pode interferir no ajustamento da conduta de pessoas cegas já que, ao se guiarem pela audição, as situações muitas vezes enganam e a comunicação fica suspensa.

Uma regra de conduta é definida por Goffman como um guia para a ação, recomendada não por ser agradável ou eficiente, mas por ser considerada apropriada. A ligação a regras leva à constância e padronização dos comportamentos e é uma fonte de regularidade nas atividades humanas. As infrações podem levar a sentimentos de desconforto e a sanções sociais negativas. Na pesquisa, alguns entrevistados demonstraram preocupação especial em cumprir certas regras ou posturas de conduta nas interações, desenvolvendo técnicas não visuais para se adequarem a elas ou demarcando a sua diferença em relação a uma condição visual.

Depois que ficou cega, Camila diz que não queria que mudasse a postura de olhar na direção da pessoa com quem está conversando, mesmo que não possa enxergá- 
-la. Aprendeu como fazer perguntando para outras pessoas cegas, que lhe disseram: "quando a pessoa estiver falando com você, você percebe a voz e olha na direção da pessoa, se você erguer a sua cabeça você vai olhar na direção da boca certinho, do queixo, começa a fazer isso que dá certo”. Ela deseja manter a postura por saber que socialmente é isso que se espera de uma pessoa. Preocupação semelhante aparece quando Beatriz assiste à televisão. Às vezes está assistindo à novela e, de repente, repara que sua cabeça está voltada para o corredor. Ela corrige e se volta para a televisão; pelo som percebe se está mais para cima ou mais para baixo. Também desenvolveu um exercício para comandar o olhar durante uma conversa, não deixar "solto", e acha que isso ajuda na aparência, impacta menos na interação. As estratégias desenvolvidas por Beatriz e Camila para controlar seus gestos e ajustar suas posturas têm por objetivo não apenas adequar sua conduta a uma expectativa social, mas diminuir o impacto da diferença da cegueira na relação com quem enxerga.

Le Breton (2009) diz que toda interação começa e encerra com uma série ritual de gestos e de palavras que colocam os atores em posição favorável para iniciar ou concluir uma troca. Começar um assunto demanda certas formas de saudação que são social e culturalmente variáveis. É o que o autor chama de "etiquetas corporais de integração". Um dos sinais indicativos da falta de visão, para Camila, foi quando as pessoas estendiam a mão para cumprimentá-la e ela não conseguia mais enxergar para estender a sua de volta. Depois aprendeu que entre pessoas cegas existe uma técnica, ou uma estratégia pensada para remediar o desconforto social gerado pela infração a uma regra de etiqueta, que é ensinada na reabilitação ou passada por outra pessoa cega: a de estender a mão primeiro para que a outra pessoa a pegue.

Embora sejam olhos que não veem, nos depoimentos fica marcada uma preocupação com o direcionamento do olhar que, como indica Goffman (1966), é uma importante ferramenta na interação focada nas situações sociais. As posturas, a correção do corpo, as alternativas desenvolvidas para o aperto de mão e para sustentar o olhar na direção da pessoa em uma conversa, ainda que não a estejam vendo, são estratégias de manipulação de sinais desenvolvidas por pessoas cegas para manter a fachada em uma interação face a face. Dora fala sobre essa preocupação de estar ou não voltada para o lugar "certo" quando conversa com uma pessoa, e do quanto demorou a perceber que essa era uma convenção social que ela, por ser cega, não cumpria, já que não encontrava utilidade para a postura na sua comunicação com as outras pessoas. 
Eu custei a perceber, porque eu acho que foi um erro das pessoas da minha família não me terem chamado a atenção disso. Acho que também não chamaram a atenção porque se acostumaram, né? Porque é o seguinte, cego começa a falar, e aí eu levanto para pegar água e continuo falando lá da cozinha, eu sei que se você pode me escutar, você está escutando o que eu estou falando. Mas as pessoas que veem, elas normalmente não fazem isso, elas falam e tem ao mesmo tempo um contato visual. Elas têm aquela ponte. E o cego não tem isso, ele fala de qualquer maneira, fala em qualquer postura, ele está fazendo alguma coisa e está falando, ele não está olhando para você, não está nem virado para você e está falando. Ele está prestando atenção em você, mas não está necessariamente olhando pra você, direcionado pra você como se fosse... visualmente, né? Porque a pessoa que vê ela entende direcionado como direcionado visualmente, mas ele pode estar direcionado auditivamente, ele pode estar virado de costas, mas ele pode estar direcionado, a atenção dele está toda em você. Só que ele não precisa estar virado, não vai adiantar nada se ele tiver virado para você, entende? Eu só descobri isso depois de velha, que eu fazia uma coisa que não era o normal que as pessoas faziam. Aí as pessoas podem não entender que eu posso não estar olhando para você, mas que eu estou prestando atenção em você.

Destaca-se no depoimento a diferença entre os estados de atenção auditivo ou visual em uma conversa. Prestar atenção com a audição não exige uma postura corporal pré-determinada, enquanto prestar atenção com os olhos demanda uma retidão e um direcionamento específico - face a face -, que inclusive limita a movimentação. Uma comunicação não visual demanda outros gestos e capacidades distintamente constituídas de prestar atenção nas dinâmicas sonoras e auditivas de uma conversa. Mas, como lembra Goffman (2011), as regras de conduta invadem o indivíduo, seja diretamente - uma obrigação que estabelece como ele é moralmente coagido a se conduzir -; seja indiretamente - uma expectativa que indica como os outros são moralmente forçados a agir em relação a ele.

\section{A funcionalidade do gesto}

Um ponto delicado, mas também importante de se trazer para a discussão sobre o gesto nas relações entre a visão e a cegueira é a ênfase predominantemente adaptativa ou funcional que muitas vezes recebe nos serviços especializados voltados para a reabilitação/habilitação. O enfoque principal dos programas de reabilitação, desde a sua origem, tem sido na recuperação ou desenvolvimento da independência funcional da pessoa com deficiência (Moreira, 2008). Especialmente a partir 
das discussões que deram origem à Classificação Internacional de Funcionalidade, Incapacidade e Saúde (CIF) ${ }^{3}$, o termo "funcionalidade" passa por um alargamento, abrangendo não apenas a funcionalidade física, mas incorporando as noções de atividade e participação social.

A pergunta que costuma nortear o trabalho clínico de profissionais da saúde que realizam os atendimentos é a de como sintonizar os corpos e os ambientes de modo a tornar a vida cotidiana de uma pessoa suportável, ou até mesmo prazerosa, apesar de impedimentos que, algumas vezes, podem ser seriamente perturbadores (Mol, Struhkamp \& Swierstra, 2009). O plano de reabilitação deve se basear não somente na presença de um órgão considerado lesionado, mas também levar em conta as necessidades do indivíduo, a relevância das tarefas para a sua vida cotidiana e seus objetivos. Devem ser planejadas metas individuais a partir das quais os resultados da reabilitação possam ser posteriormente medidos. O atendimento conhecido por Atividades da Vida Diária está pautado nas técnicas cotidianas do corpo, remetendo a certos costumes que também podem ser relacionados ao corpo civilizatório descrito por Elias (1994) - hábitos de higiene, vestimentas, modo de se alimentar, regras de etiqueta. A estimulação precoce, por sua vez, por estar voltada para crianças de 0 a 3 anos, traz uma forte preocupação com o desenvolvimento psicomotor. Dora coloca suas impressões sobre esses atendimentos:

As pessoas pensam no funcional, que aquela pessoa não pode ficar com um déficit motor, na marcha, na mobilidade. Não pode atrofiar. O que está muito certo, que não pode mesmo. Só que eu acho isso pouco. Você fala de estimulação. Primeiro questiono o precoce, por que precoce? É estimulação adequada, não é precoce. Segundo que você centrar só no funcional? Cada vez mais eu me dou conta do quanto de informação que eu não tenho e do quanto de feedback que eu não tenho por ser cega. E o fato de eu não ter esse feedback, nem dos outros, de não saber como é a expressão dos outros, nem a minha, faz com que eu também não tenha o controle dos meus músculos faciais, faz com que eu não tenha essa consciência e esse controle. Fora todas as informações posturais, das outras pessoas, eu não tenho essa informação. O que acontece com a estimulação precoce? Procura se desenvolver movimentos para a criança poder ter autonomia, poder se locomover bem, poder se desenvolver legal. Como questão motora, como função. Beleza. Agora, e o corpo como expressão? Acho que as pessoas não têm essa noção. Eu acho que a estimulação precoce tinha que incluir isso. Expressão corporal, expressão facial e essa comunicação de informação gestual. Para mim são três coisas. São três coisas que a gente fica fora, literalmente fora. 
Foi também o caráter social e eficaz da técnica que Mauss (2003) ressaltou quando fez um inventário das variações de movimentos corporais como a marcha, a educação do andar, as técnicas de higiene e de cuidado com o corpo. O autor considerou que não há técnica se não houver tradição, ainda que o ato seja sentido por aquele que o realiza como de ordem mecânica ou físico-química. O aprendizado das formas de se mover é mimético, fruto de um processo de adestramento somático que acaba reduzindo as técnicas corporais às normas sociais, cuja eficácia é medida pelo seu "rendimento" (Mauss, 2003: 410). A ênfase é no caráter utilitário e produtivo da ação: "as pessoas que têm o senso da adaptação de seus movimentos bem coordenados a objetivos, que têm hábitos, que 'sabem como fazer'. É a noção inglesa de craft, de clever (destreza, presença de espírito e hábito), é a habilidade em alguma coisa" (Mauss, 2003: 411).

Se, por um lado, a ênfase na funcionalidade da (re)habilitação traz a preocupação da autonomia, independência e da inclusão de corpos considerados diferentes na sociedade, por outro, não questiona as próprias bases e padrões sociais pelos quais a sociedade se constrói, voltada para um corpo único, normativo. O funcionamento do corpo deficiente e o grau de participação social da pessoa com deficiência ainda é medido em função de sua maior ou menor adaptação a regras e padrões sociais de interação que se constroem a partir do funcionamento de outro corpo, aquele considerado “capaz" ou "normal”. O ponto está também explicitado no item anterior, na preocupação com o desenvolvimento de estratégias corporais de adaptação de pessoas cegas às convenções sociais de interação.

O foco na funcionalidade pode acabar se mostrando uma tentativa de inclusão por meio de uma manobra excludente, por estar ainda pautada pela estratégia da normalização. Como lembra Reynold (2017), o corpo deficiente foi sempre considerado uma variação corporal do corpo normativo. Esse último, a figura ideal ou exemplar do capacitismo: forma de vida constituída por e assegurada pela sua participação na normalidade. O termo normativo (normate), conforme definido por Garland-Thomson (1997), designa a figura social por meio da qual as pessoas costumam se representar como seres humanos definidos. É essa figura socialmente constituída que definirá os padrões de funcionalidade em relação aos quais a deficiência será constituída como incapacidade, assegurando com isso as fronteiras da normalidade.

Moser (2000) identifica uma ambivalência que acredita ser uma consequência lógica, um efeito esperado quando políticas, inciativas e práticas de cuidado se norteiam pela normalização: o desejo de ajudar pessoas com deficiência e efetivamente 
melhorar suas vidas, por um lado, e o fato de que as diferenças são definidas como faltas ou desvios que devem ser compensados ou corrigidos, por outro. Tal como utilizada aqui, a noção de técnica ou de funcionalidade inspira um caráter utilitário para a ação. Ao final do programa teremos organismos que foram diferentemente “disciplinados" (Foucault, 2013), mas que estarão mais ou menos aptos a se (re)inserirem numa sociedade que, por sua vez, permanece intacta, ordenada pela mesma lógica produtiva, "normal”, capacitista e visuocêntrica.

A ênfase na funcionalidade imprime uma direção prática para os atendimentos, em detrimento das variações, das transformações, dos infinitos e criativos modos de se realizar um gesto ou um movimento. São ações voltadas para atingir determinado "fim" - seja o desenvolvimento sensório-motor, seja o desempenho de tarefas rotineiras, seja a aprendizagem de convenções sociais. A proposta que se descortina não é substituir a ênfase na funcionalidade e no desenvolvimento motor das ações educativas voltadas para pessoas cegas por outra ênfase supostamente mais "adequada", e sim adicionar novas vias que escapem aos processos de adestramento do corpo deficiente, instaurando proposições que o abram à experimentação e ao universo intensivo.

\section{“A palavra vence a cegueira?” Gesto, cultura e linguagem}

Os atores de Goffman (1966) parecem estar imersos em uma sucessão constante de cálculo, preparação e estratégias desenvolvidas para controlar suas condutas, ajustar suas máscaras, manter sua face diante de um outro genérico neste palco que é a vida social. A copresença física dos indivíduos no espaço público sob o prisma goffmaniano da "situação" envolve a ocorrência de, ao menos, três mecanismos normativos (Frehse, 2009): o manejo das impressões do self - a imagem que o indivíduo tem de si a partir da imagem que outros têm dele; a adoção de uma sequência densamente simbólica de gestos e posturas, de cunho ritual; a transmissão corporal de mensagens sobre os sentidos das interações através do chamado "idioma corporal". Como Dora coloca no depoimento anterior, o foco na funcionalidade e no desenvolvimento motor, se por um lado privilegia a independência e a autonomia, por outro aparta as pessoas cegas de um importante componente da cultura, atualizado na gestualidade comunicativa dos corpos. A comunicação pode ser entendida não como um ato individual, mas como instituição social, como performance da cultura (Winkin, 1998). Dora fala sobre a sua descoberta do papel dos gestos na interação: 
Eu minimizava isso, eu subestimava, a questão dos gestos e a questão da minha própria expressão facial. Porque é como se eu me achasse menos... menos diferente. Eu achasse que isso fosse menos relevante. E de repente eu saquei a relevância disso, tanto a relevância dos gestos que eu não estou vendo, a relevância de gestos que eu não estou fazendo. A relevância das caras que eu não estou vendo e como eu não estou vendo também não sei fazer. É como se eu achasse que isso fosse muito mais irrelevante para a minha relação com as pessoas, mas não é.

Birdwhistell (1990) se dedicou a compreender os movimentos do corpo durante as interações como uma forma de linguagem. No processo de nos tornarmos humanos, um sistema de comunicação é internalizado. Ganhar controle da linguagem, entretanto, não é a simples acumulação de um agregado de palavras ou um determinado tamanho de vocabulário. Envolve a corporificação de um complexo sistema de movimentos, comportamentos e gestos que também constituem formas comunicacionais. $\mathrm{Na}$ análise cinésica, as gestualidades, as mímicas ou as movimentações não são isoláveis do sistema global de comunicação, que também inclui a língua, os silêncios ou a tonalidade da voz. O espanto de Dora com a abrangência da gestualidade é significativo. Assim como não existem palavras universais, nenhum som complexo que carregue o mesmo significado mundo afora, não existem movimentos corporais, expressões faciais ou gestos que provoquem respostas idênticas. A comunicação corporal é moldada pela cultura.

A ênfase maior no corpo funcional começa na educação de cegos em torno de uma idade específica, 6 anos. Não é arbitrária a coincidência dessa faixa etária com o desenvolvimento da linguagem verbal. Se a posse do verbo foi sempre considerada a manifestação de uma espécie de prova de plena pertença à humanidade, como sugere Le Breton (2009), compreende-se porque Vygotsky considerou que, apesar das limitações físicas de movimento, o cego como personalidade, como unidade social, teria perdido menos que o surdo, uma vez que, para o autor, "a palavra vence a cegueira" (Vygotsky, 1997:108). Vygotsky defende que as possibilidades compensatórias deveriam ser a força motriz do processo educativo da criança deficiente. No caso da deficiência visual, a fonte da compensação não seria “o desenvolvimento do tato ou a maior sutileza do ouvido, mas a linguagem, quer dizer, a utilização da experiência social, a comunicação com os videntes” (1997:107).

A frase sugere um direcionamento para as práticas educativas que de certa forma esterilizam a possibilidade de se considerar as diferenças perceptivas - a maior sutileza do ouvido ou o desenvolvimento do tato - como potências singulares da 
cegueira. Acaba-se priorizando aquilo que supostamente aproxima ou iguala a experiência da cegueira da experiência da visão: a comunicação centrada na linguagem. Se pensarmos nos tempos atuais, em que a Libras foi reconhecida como segunda língua oficial do Brasil ${ }^{4}$, o destaque ainda atribuído à linguagem verbal na educação de cegos como compensação social da cegueira, ou mesmo na audiodescrição como forma privilegiada de acesso à cultura para pessoas com deficiência visual, parece ter como efeito colateral mantê-las apartadas de todo um universo cultural gestual significativo.

O enfoque no canal sonoro se explica, por um lado, pelo uso que pessoas cegas fazem da audição como forma de controle do ambiente e interação com as pessoas ${ }^{5}$, mas também parece se justificar pelo aspecto facilitador da interação com videntes. Há que se questionar se, nessas práticas, a cegueira não acaba sendo normatizada tendo como critério a experiência perceptiva de mundo centrada na visualidade. A pessoa cega compreenderá o que acontece em uma cena acessando "por tabela" a experiência visual de quem enxerga, que deve ser comunicada/traduzida verbalmente para aqueles que não veem, em um processo unidirecional de transmissão de informações.

Investir no Braille, no desenvolvimento de materiais táteis ou em formas multissensoriais de acesso à cultura significa, por outro lado, reconhecer a diferença e a especificidade de um modo de estar e agir no mundo que pessoas que enxergam não dominam, a não ser por meio de um esforço necessário de interesse pelo outro em sua singularidade e de abertura para o aprendizado. Mais uma vez, a questão aqui não deveria ser de substituição, mas de ampliação. Como coloca Dora,

essa questão da estimulação vem muito de uma linha da pedagogia, fisioterapia, educação física, psicomotricidade, entendeu? E não vem da arte. Não tem arte na educação da pessoa cega. Ou tem, mas fica pobre. Quando se pensa em educação, você pensa só a questão funcional. Na verdade, não tem arte para ninguém. Mas acontece que a criança que vê ela olha nem que seja o muro grafitado, ela olha uma foto, ela olha o desenho, ela faz o desenho, ela vê novela. Eu, por não ter o feedback visual, não consigo ter o domínio total da minha máscara. Eu não consigo ter controle.

Um rosto sem máscara é um rosto sem marca, sem cicatrizes que o remetam a novas composições. Rolnik chama de marca "os estados inéditos que se produzem em nosso corpo, a partir das composições que vamos vivendo” (Rolnik, 1993:242). 
Embora todos os corpos sejam tencionados pelas forças da produtividade que nos disciplinam, corpos que enxergam encontram linhas de fuga para o desenvolvimento de outras formas de viver e se expressar no seu cotidiano ao observarem uma fotografia ou o desenho grafitado em um muro, como diz Dora. O mesmo não acontece com corpos que não enxergam, que precisam não tanto de explicação verbal, mas de mediação e estímulo ao movimento como oportunidades para desenvolver a consciência corporal e expressiva. Esse não é um corpo submetido às exigências de uma ação sensório-motora - seja da saúde, do trabalho, do esporte, das ações cotidianas ou de qualquer outro tipo de atividade -, mas um corpo que existe como movimento, destacado de todas as determinações práticas, que se abre e se modifica pelos fluxos, ritmos e vibrações que o atravessam.

\section{Arte, movimento e expressividade}

Dora sente que houve um déficit na sua formação na parte da expressão. Ao se dar conta do alcance desse déficit, foi percebendo que está ligado à anatomia do rosto, aos músculos que não aprendeu a mexer, aos movimentos que não sabe como fazer. Ao longo da pesquisa, com o privilégio da relação de amizade que desenvolvemos, pude acompanhar mais de perto o alcance da temática e as marcas dessa exclusão, que ela corajosamente busca recuperar.

Tem duas coisas para mim, duas frustrações totais que eu nunca consegui participar. Uma é aquela brincadeira de mímica - "qual o nome do filme?" - eu sou incapaz. Mímica de filme, mímica de música, isso para mim não é uma brincadeira, isso para mim é uma morte, é uma tortura. Porque eu não tenho a menor noção, eu não sei fazer nada, eu não sei como fazer. Eu já não estou nem querendo como descobrir, como descobrir eu posso até passar a mão na pessoa, sei lá. É você não ter aquele vocabulário, é você não ter aquele universo, você não falar aquela língua. Para mim é uma coisa que sempre me deu curto-circuito. "Vamos brincar de mímica?", para mim era pânico, eu entro em pânico, porque é uma coisa que dá aquele sentimento de impotência, sabe essa sensação? De você dizer assim "ai, não vai dar para mim, essa aí eu estou fora”. Mesmo sabendo racionalmente que é tudo uma brincadeira, mas é um desconforto. A outra coisa é o motivo pelo qual eu nunca fui fazer Tai Chi, porque a sessão que eu fui de Tai Chi era aquele negócio de fazer os bichos. Eu não sei fazer bicho nenhum, gente. "Faz o bicho não sei qual, faz como o bicho não sei qual, faz o tigre”. Eu não sei fazer os bichos. Eu não vejo os bichos, eu não sei. 
Embora seja também linguagem (“é você não falar aquela língua”), entender pelas palavras não é o mesmo que entender pelo movimento, a descrição meramente verbal não dá conta. Uma coisa é saber o que é um tigre na sua relação prática com o ambiente em que ele vive - do que se alimenta, qual o seu habitat, se é gregário, se migra, se é um animal de hábitos noturnos ou diurnos. Outra coisa é entender o papel simbólico do tigre a partir da forma como a cultura o significa relacionando-o a outros signos - a ferocidade, a bravura, a força. Ter acesso ao conhecimento dos dois tipos anteriores esgota tudo aquilo que um tigre é?

Qual é a importância de conhecer o movimento do tigre para a compreensão do modo de existência do tigre? Tudo aquilo que um tigre é está marcado pela forma como ele se movimenta. Tanto a sua ferocidade quanto os seus hábitos alimentares não estão desvinculados das maneiras pelas quais um tigre se move. E, se nós não podemos ser tigres para compreender isso, podemos aprender um pouco mais sobre este animal e sua experiência vital ao imitar seus movimentos - ao menos é isso que práticas ancestrais como o Tai Chi Chuan, a capoeira ou rituais indígenas xamânicos nos ensinam. Este é um tipo de aprendizado prático e afetivo, que passa pela experiência corporificada, uma forma de "compreensão encarnada" (Rabelo, 2011). Não se trata de transmitir conteúdo, mas de, por meio de uma alteração nas formas ordinárias de engajamento e uso corpóreo (Jackson, 1989), abrir novos agenciamentos e novas possibilidades para a composição de imagens de um tigre.

Rodrigues (2014), que tem uma prática educacional há mais de 30 anos no IBC, especialmente dedicada ao trabalho com crianças pequenas na Estimulação Precoce, compartilha em sua tese o que os anos de experiência profissional a permitiram observar sobre como os corpos que não enxergam costumam se movimentar:

O pouco manejo com o corpo presente em grande parte das pessoas cegas é um fato que sempre me chamou a atenção, desde que iniciei como professora do IBC. A falta de molejo se mostra por uma postura um tanto rígida, caminhar tenso e movimentos pouco flexíveis, sem as dissociações de cintura próprias da marcha e, adicionalmente, muitos apresentam dificuldade de se expressar corporalmente. (...) A tensão da musculatura que assumem parece atuar como fator de proteção à dor quando obstáculos são frequentes e inesperados no cotidiano dessas pessoas. Elas ficam mais facilmente expostas a pancada e a quedas, que poderiam ser evitadas com a visão. (Rodrigues, 2014:86)

Laban (1978) considera que o aprendizado da língua não exige somente a 
memória linguística ou a capacidade de gerar frases, mas requer a encenação da palavra. Esta, por sua vez, demanda ritmo, tonalidade da voz, movimentos do corpo, do rosto, atitude, esforço, o desempenho de determinadas posturas. O movimento, apesar de ser um processo constante de mudanças contínuas, possui padrões singulares de ordenações rítmicas. O autor desenvolveu uma espécie de partitura de movimento, semelhante à musical, em que descreve ações corporais com o objetivo de introduzir o estudante do movimento a exercícios destinados a treinar o corpo, não tanto para aprender a se comunicar, mas para se tornar um instrumento de expressão, enfatizando tanto a parte fisiológica quanto a parte psíquica que levam o ser humano a se mover.

Trabalhar a percepção do gestual e elaborar propostas que incentivem formas distintas de se movimentar, de modo a ir além de um lugar objetivado do corpo como instrumento para realização de atividades práticas / funcionais, é uma demanda evidente de pessoas cegas para o desenvolvimento de sua expressividade. Dora, ao tentar explicar como sente esta lacuna, faz uma comparação com os movimentos desempenhados por um artista em seu processo criativo:

Imagina um pianista. O pianista ele tem o controle motor dos dedos, né? Preciso. Milimétrico. A pessoa que não tem aquele treinamento, ela nem sabe como é que faz para conseguir fazer aquilo que ele faz. Não é assim? A mesma coisa o pintor, o pintor tem aquela destreza, o pincel obedece ele no milímetro, no mínimo, naquele micro... é aquela técnica, mas é um treinamento, é um adestramento muscular. É como se eu não tivesse esse adestramento muscular da face, para fazer aquelas coisas, aquelas sutilezas... é como se eu não tivesse esse adestramento, que eu acho que eu realmente não tive. Então eu acho que tem coisas que me faltam. E eu não sei nem o que é que falta, eu sei que falta. E isso é uma coisa que eu nem sei medir o quanto que é diferente a minha expressão. Eu não sei medir.

A descoberta da abrangência e da expressividade do gesto teve, para Dora, o efeito revelador de um desajuste na sua própria autoimagem em relação ao mundo externo, aquele das pessoas que enxergam. Ela passa a notar em si, enquanto pessoa cega, uma diferença que antes não conhecia. Quando fala dos movimentos do artista, o adestramento é importante, mas a sutileza do gesto é distintiva. Se não há um código igualmente rigoroso para os movimentos do corpo como o alfabeto seria para a linguagem, se os gestos são fugazes, polissêmicos, ambíguos a ponto de não se deixar apreender em categorias transparentes, a arte, mais especificamente 
o teatro e a dança, são os campos que melhor aprofundaram, na prática, a compreensão e o desenvolvimento de técnicas de treinamento e estímulo da expressividade e dos movimentos corporais.

A intermediação da arte no trabalho com pessoas cegas vem sendo realizada na iniciativa precursora de alguns artistas e pesquisadores que desenvolvem oficinas que incluem recursos artísticos e expressivos como metodologias fundamentais ${ }^{6}$. São locais que abrem espaço para a experimentação corporal dos gestos por pessoas cegas para que se produzam variações nos modos de construção e expressão de si. A proposta não é necessariamente que se aprenda a executar este ou aquele gesto a ser utilizado em tal ou qual situação, mas ampliar o repertório de gestos, criar uma memória cinética e afetiva, estimulando uma atitude de abertura para o mundo com o corpo inteiro, um estado de atenção e conectividade com o outro e com o ambiente.

Uma das situações descritas por Moraes (2007) sobre uma atividade desenvolvida em uma oficina de expressão corporal no IBC em que se buscava fazer compreender o movimento da bailarina a uma aluna cega, ilustra bem a limitação das palavras para descrever um gesto, de que nos fala Le Breton (2009), e a diferença entre a gesto funcional ou verbal e o gesto expressivo que estamos tratando.

Uma menina cega congênita que representaria a personagem da bailarina não conseguia entender o que lhe diziam a respeito dos movimentos da sua personagem - rodopiar com leveza pelo palco. Ela entendia o sentido das palavras - que a bailarina é leve, que ela dança levantando as mãos e gira em torno do próprio corpo -, mas isso não era suficiente para que conseguisse devir-bailarina, isso é, encarnar, corporificar o movimento. A simples explicação do que é ser bailarina se mostrou pouco eficiente, a menina não era afetada pelas palavras, não conseguia se modificar a partir do que ouvia. Pesquisaram-se mecanismos de tradução que produzissem um deslocamento do universo das palavras para o dos sentidos e das experiências corporais. Para que a menina entendesse a personagem bailarina participaram o som da música, o tatear de peças do vestuário da bailarina e, para que compreendesse a leveza do movimento, a mediação de um grande balão de gás preenchido com grãos de arroz de forma que, com a circulação, produzisse um som suave. Com o movimento dos braços articulados ao balão - abraçar na frente do corpo, levantar no alto da cabeça, levar para o lado - foi possível construir com a menina os movimentos e a leveza dos braços da bailarina (Moraes, 2007; Moraes, Cardoso-Manso \& Lima-Monteiro, 2009). 
Não poder ver a bailarina não significa que o movimento não possa se desenvolver de outras formas que não a descrição verbal, que parecia incapaz de transmitir sua essência movente. A especificidade do gesto é justamente a de ser diferente da linguagem verbal, transferir um registro físico a um registro verbal faz com que se perca o contexto e a sua especificidade. Laban (1978) introduziu a ideia de se pensar em termos de movimento em contraposição a se pensar em palavras. O pensar por movimentos é considerado por ele como um conjunto de impressões de acontecimentos. Acontecimentos que têm que ser vividos.

Gil sugere existir um "espaço do corpo" que não se confunde com o espaço objetivo que ocupa, mas que "prolonga os limites do corpo para além dos seus contornos”, é um “espaço intensificado” (Gil, 2001:57,58). É a criação desse espaço corporal intensificado que o encontro entre arte e cegueira pode fazer emergir. Rodrigues considera que a oficina de expressão corporal que realizou com jovens cegos alunos do IBC proporcionou a abertura de um espaço onde eles podiam

quebrar a carapaça e produzir outro corpo, promovendo a conexão com outros elementos, com uma diversidade de materiais (bola, argila, bambolês), com os colegas, com a música, com o ambiente, na intenção de produzir um corpo mais confiante de si, bem diferente daquele que parecia uma armadura. (Rodrigues, 2014:86).

O trabalho com a arte pode, potencialmente, instaurar nos participantes, deficientes visuais ou não, aberturas para a criação de novos corpos intensivos e novas formas de subjetivação. A partir da proposição de composições - com os outros, com o ambiente, com materiais -, estimular rearranjos capazes de instaurar marcas (Rolnik, 1993), ampliando as formas de afetar e serem afetadas das corporalidades presentes. A experimentação é a condição desse tipo de trabalho, e a repetição será um dos meios de estabelecer não exatamente similitudes, mas diferenças.

Para um ator cego, a construção corporal da personagem ou a "expressão de si” (Goffman, 1996) não passa pela imitação, em um sentido estritamente visual. Outros recursos precisam ser criados. Na oficina "Teatro, Criatividade e Imaginação", que realizei em parceria com Clara de Andrade no IBC, desenvolvemos a "fotografia corporal" dos gestos, em que o toque dos participantes naquele que realizava uma postura permitia a apreensão da sua expressão corporal pelos colegas. Mas a técnica dependia da estratégia de "estátua", congelar o gesto por tempo suficiente para que os outros participantes pudessem tatear e compreender. Para esti- 
mular movimentos diferentes do cotidiano, como o mergulho no mar, ou a travessia por uma trilha densa em uma floresta imaginária, utilizamos nossos próprios corpos como estratégia para o direcionamento de algo que queríamos mostrar ou como forma de ampliar as possibilidades de movimento trazidas pelos participantes, de forma semelhante à descrita por Gonçalves: "atrizes videntes colavam o seu corpo ao corpo das atrizes cegas, esta junção corporal permitia que as atrizes cegas percebessem maneiras diferenciadas de utilizar o corpo no espaço cênico, seja com relação à lateralidade, planos e profundidade” (2009:49).

O que se vê aqui são estratégias inventivas que permitem a imitação dos movimentos por quem não enxerga. Bruno (2009), que desenvolve um trabalho atento às possibilidades expressivas do movimento na Educação, usa a expressão "movimento coativo" para se referir ao modo de ensinar a imitação para uma criança cega:

A criança com deficiência visual aprenderá a imitar, cumprimentar e a brincar se encontrar pessoas disponíveis para interagir, com movimentos coativos. Esses movimentos são importantes para a compreensão da ação, permitindo o jogo imitativo de um modo diferente daquele que a criança vidente realiza. Para produzir movimentos coativos, pode-se encaixar a criança no meio do corpo do educador (pais, professor ou outros profissionais) e pelo contato físico ela compreenderá tátil-cinestesicamente os movimentos e ações realizados pelo outro (Bruno, 2009:133).

O ser social é “imitador por essência” (Tarde, 2000:13) mas imitar, para Tarde, não é fazer igual. Pelo contrário, imitar é diferenciar-se, é na imitação que se engendra formas inovadoras. Com a proposta de arte encarnada, a oficina Imagens Vivas, criada por Gonçalves (2009), propõe a reprodução corporal de obras de artes plásticas conhecidas, que envolvem a figura humana, por atores que enxergam para que as pessoas cegas participantes, por meio do tato, possam primeiro conhecer a composição corporal das figuras e, em seguida, reproduzi-las em seu próprio corpo para experimentar os efeitos provocados pela postura. Dora, que participou das oficinas, descreve suas impressões:

Quando eu fui fazer através daquilo que eu tinha percebido no corpo dele, aí caiu uma montoeira de ficha, atolou o orelhão de tanta ficha. Primeiro eu me dei conta do quanto a gente não está acostumado, no dia a dia, a tocar o corpo das pessoas. Então quando a gente toca, mesmo que a proposta seja aquela, você fica 
meio tímido para fazer aquilo, de sair tocando, vendo assim músculo por músculo, dedinho por dedinho como é que está aquela pessoa. Segundo que mesmo que você consiga ultrapassar esse sem jeito, essa timidez, como você não está acostumado a tocar, a sua mente não está acostumada a reter toda aquela informação gestual, porque é uma coisa que você não está acostumado no seu dia a dia. (...) Você está conversando comigo e está olhando todos os gestos que eu estou fazendo, se eu boto a mão para cima, se eu boto a mão para baixo, se eu viro para o lado, se eu viro para cá... e eu não estou vendo os gestos que você está fazendo, então como é que eu não ter esse exercício de ver os gestos dificulta na hora que então eu vou lá, toco uma pessoa e depois vou reproduzir, como é que eu ainda estou primitiva em relação a isso, como é que eu fico torpe né? Porque é uma coisa que eu fiz muito menos na vida.

Se os gestos, as mímicas ou as "caras" utilizadas pelas pessoas no dia a dia não podem ser imitadas visualmente por pessoas cegas, a linguagem corporal, por meio do tato, possibilita o aprendizado. Espaços que rompem com as restrições sociais ao toque permitem entrar em contato com esse reservatório gestual, através de iniciativas que têm como proposta a pesquisa expressiva. As oficinas, como espaços de criação, permitem o desenvolvimento de técnicas singulares de observação, imitação e cópia na cegueira que são necessariamente inventivas (Sautchuk; Derbotoli, 2013). A técnica pode ser vista aqui não como um produto objetivável, mas como uma forma sempre nova de acoplamento com as mais diversas situações, ambientes, coisas, pessoas e instrumentos. Importante ressaltar que no caso relatado por Dora, os participantes eram pessoas cegas e não cegas, a interação entre as duas formas de estar no mundo possibilitando a troca e o aprendizado. Para os dois lados, ela diz:

Quando eu fui fazendo, ele ia consertando as coisas que eu fazia errado porque não tinha guardado direito, mas ele também consertava as próprias imprecisões dele mesmo, ele ia sacando assim, "ih isso aqui eu acho que eu não fiz legal não”... através de mim ele ia refinando a própria percepção dele. Então uma coisa legal que eu vi naquele exercício foi como que, através dessa experiência com a pessoa cega, o próprio ator pode refinar o seu próprio gesto. (...) Meu trabalho com atores é esse de eu poder ganhar de alguma forma, pelo menos em parte, esse recurso. Eu quero ganhar esse recurso. De comunicação. Ganhar esse controle de mim mesma. E quero ter esse feedback da minha expressão. Porque quando você não está se vendo, muitas vezes você não tem o ajuste fino da sua própria expressão. E eu tenho certeza que no trabalho de ganhar esse recurso expressivo eu também vou estar propiciando que o ator aumente os dele, porque na hora que 
ele tiver que me explicar com palavras o quê que é, ele vai aumentar a consciência dele mesmo sobre os recursos dele.

Grande parte das nossas ações corporais diárias são inerentes às necessidades humanas essenciais, como caminhar, sentar, comer, levantar, etc., mas a atitude corporal é um aprendizado que se expressa nas infinitas possibilidades de como realizar essas ações (Laban, 1978). A experiência entre visão e cegueira, compartilhada por Dora e pelo ator com quem fez o trabalho, possibilita um espaço para a pesquisa infinita de gestos e movimentos atravessados pela diferença. O equívoco e a repetição dos gestos promovem a abertura de um espaço para o ajuste, o refinamento, a conscientização, a transformação de si através do contato e da composição com o outro. Como sugere Silva,

o equívoco gestual se refere ao caráter sempre conjectural da experiência, inclusive o das nossas experiências íntimas e imaginativas. Habitar essa equivocação significa, portanto, abrir-se a uma especulação potencialmente infinita dos movimentos (Silva, 2016:27).

Cada gesto provocado nas oficinas funciona como um ato de engajamento e participação, convidando os participantes não tanto ao desempenho de uma atividade com um teor funcional ou prático pré-determinado, mas a um ato de experimentação e improviso. O que se promove no desempenhar dos gestos são aberturas para a invenção de modos de solucionar corporalmente provocações motoras / culturais que nunca se repetem perfeitamente (Sautchuk; Derbotoli, 2013). Pensada neste sentido, as técnicas e os gestos desenvolvidos estariam mais próximos da noção de habilidade, enquanto um processo de produção e transformação do mundo que emerge nas práticas corporais nas quais os sujeitos se engajam (Ingold, 2015).

A técnica muitas vezes é tratada como um conjunto de saberes prontos, disponíveis para reprodução por imitação. Entretanto, na esfera da dança, dominar bem uma técnica não significa dançar bem, a técnica é entendida como condição necessária, mas não suficiente (Katz, 2009). Depois da técnica, é preciso superá-la. A superação seria a conquista de um modo próprio de lidar com o conhecimento que advém da técnica. Para Greiner e Katz (2001), no corpo humano estão as evidências da inevitabilidade de ser contaminado e de contaminar. Corpo como uma porta de vaivém que promove e rompe contatos. Cada tipo de aprendizado traz uma rede particular de conexões ao corpo. Quando se aprende um movimento, aprende-se 
junto o que vem antes e o que vem depois dele. O corpo se habitua a conectá-los. Desenvolver técnicas de imitação do movimento e a consciência da expressão corporal, de que cada parte do corpo pode ser um signo, mesmo quando o sentido visual não é preponderante ou é inexistente, é uma das contribuições substanciais que as formas de expressão artística podem provocar no campo da cegueira.

\section{Considerações finais}

As experiências relatadas sugerem que o encontro entre a arte e a cegueira é capaz de ampliar os poderes do corpo que não enxerga, expandindo tanto a sua potência de agir quanto a sua sensibilidade expressiva. A bela análise e tipologia do gesto proposta por Silva (2016) nos ajudam a retomar a problemática gestual na relação entre visão e cegueira não como um mal-entendido ou desajuste na comunicação, mas como um chamado.

Pensar a problemática do gesto na cegueira como questão relativa às técnicas funcionais do corpo pode ter o efeito de contornar o problema da emergência das formas e dos motivos - daquilo que nos move. O movimento acaba sendo tratado a partir de sua eficácia, recorrendo, para tanto, a uma externalidade que, em sua vertente culturalista, é localizada em alguma transcendência - seja a tradição, seja a textualidade. As sucessivas reduções do gesto - à funcionalidade prática ou à função comunicativa - se tornam também instrumentos de exclusão e controle que acabam submetendo a existência singular de corpos que não enxergam à lógica dominante da visualidade.

O adjetivo "expressivo" para qualificar o gesto que busquei delinear aqui se refere tanto à vivacidade ou a energia (Silva, 2016), quanto a sua ligação com o universo dos afetos. Embora a civilização ocidental tenha efetuado a separação entre os sentimentos e os gestos ou movimentos musculares, transformando a expressão de um sentimento em uma exteriorização de uma interioridade, como sugere Elias (1990), o gesto que estou chamando de expressivo é aquele em que o movimento emerge de uma corporalidade que está em relação de continuidade - em sintonização - com o ambiente e com os outros. Concordo com Silva quando diz que os gestos que realizamos e os que observamos estão dentro das condições de possibilidade da nossa experiência corporal e acredito que um dos efeitos que a arte pode ter sobre nós é de, ao intervir para expandir nossa experiência corporal, ampliar as condições de possibilidade perceptivas e expressivas do gesto. Nessa qualidade, o gesto não é um elemento a mais que se soma ao corpo para ajustar a conduta - seja 
à cultura, à sociedade ou à linguagem - mas a própria emergência de um plano de conectividade ou associação (Silva, 2016).

Ao longo do artigo foram identificadas duas modalidades de imitação, duas maneiras distintas de copiar aquilo que os outros fazem nas práticas entre visão e cegueira. Uma com o intuito normativo de aproximar os gestos da cegueira à visualidade a fim de tornar pessoas cegas capazes de agir socialmente "como se" fossem normais (Winance, 2007). Outra com o propósito criativo de ampliar o repertório de movimentos, acessibilizando o conhecimento cultural corporificado nos gestos e propondo novas aberturas e conexões a partir das singularidades perceptivas presentes. Se os gestos que nos interpelam, e que somos capazes de observar, precisam estar dentro das condições de possibilidade da experiência corporal que acumulamos, o encontro entre arte e cegueira promove precisamente ocasiões que permitem, por meio da experimentação de posturas e movimentos, na relação com outros corpos, com materiais e o ambiente, dilatar as condições de possibilidade de existência dos corpos.

$\mathrm{O}$ artigo foi principalmente estruturado no sentido de explorar as ações desenvolvidas por uma sociedade visuocentricamente centrada para adaptar / incluir pessoas com deficiência visual - seja para elas, seja com elas -, ações que, como espero ter ficado claro, apresentam suas variações no grau de abertura e envolvimento com a diferença da cegueira. Em outro momento, o desejo é o de desenvolver uma reflexão simétrica que articule as contribuições do universo corporal e perceptivo da cegueira para as formas comunicativas humanas, a partir do que corpos cegos em interação são capazes. A proposta, então, será na direção de abrir os "horizontes imaginativos" (Crapanzano, 2005) da expressão visual para as potencialidades inventivas da experiência da cegueira, entendida como um conjunto de condições sensoriais e físicas que permitem a criação de um mundo (Reynolds, 2017).

Recebido: $14 / 02 / 2019$

Aprovado: 02/05/2019 
Olivia von der Weid é professora do Departamento de Antropologia da Universidade Federal Fluminense (UFF). Desenvolve pesquisas sobre corporalidades, percepções e sentidos, sobre as relações de interdependência, cuidado e autonomia na experiência da deficiência e investiga as práticas e as relações humano-animais na formação de cães-guia. ORCID:0000-0003-0433-6890. Contato: oliviaweid@, gmail.com

\section{Notas}

1. As oficinas fizeram parte da metodologia desenvolvida no doutorado, em que investiguei a percepção de mundo de pessoas cegas (von der Weid, 2014). Durante o mês de abril de 2011 participei da Oficina Inclusiva, um workshop de teatro de 48 horas que ocorreu na Caixa Cultural, ministrado por AnaLu Palma e Inny Accioly, que propunha trabalhar recursos corporais expressivos, como os gestos, as mímicas e o movimento, e ainda as possibilidades de comunicação e representação em cena de atores cegos e não cegos. Juntamente com Clara de Andrade, desenvolvi posteriormente a oficina "Criatividade, teatro e imaginAção", por um ano e três meses, como voluntárias, para frequentadores do Instituto Benjamim Constant, localizado no bairro da Urca na cidade do Rio de Janeiro. A ideia era desenvolver uma abordagem não apenas discursiva sobre a cegueira, mas onde os exercícios corporais e jogos teatrais pudessem servir de estímulo para aprofundar questões relativas aos usos do corpo como recurso expressivo por pessoas cegas e ao estigma advindo da deficiência visual.

2. Dora tinha cerca de 60 anos de idade no período em que se realizou o campo para esta pesquisa. Ela é considerada congênita em função de um tipo específico de retinose pigmentar. Embora considerada cega de nascença, teve uma porcentagem muito baixa de visão periférica. Nunca viu cores, mas conseguiu diferenciar claro e escuro e ter noção de perspectiva. Quando criança, sua família morava no bairro da Penha, localizado na Zona Norte da cidade do Rio de Janeiro e, em função da localização, ela precisou estudar dois anos como aluna interna do Instituto Benjamin Constant (IBC), dos 6 aos 8 anos. Depois completou os estudos em uma escola de ensino regular onde sua tia lecionava. Formou-se em psicologia pela UFRJ e hoje em dia atende como psicóloga, mas também tem uma empresa que presta serviços de acessibilidade na web. Na década de 1970, Dora ajudou a criar e fez parte do "Movimento de cegos em luta por sua emancipação social". Foi casada três vezes; o último casamento durou 13 anos. Não teve filhos e atualmente vive sozinha em um apartamento no bairro da Glória, na Zona Sul do Rio de Janeiro.

3. Publicada pela Organização Mundial de Saúde (OMS) em 2001, a CIF indica que a deficiência é resultado de uma interação dinâmica entre condições de saúde e fatores ambientais, sociais e pessoais. Ver Diniz, Medeiros e Squinca (2007) para uma reflexão crítica sobre a tradução dos termos disability e impairment na versão brasileira da CIF e as implicações políticas desta opção.

4. Conforme presente no artigo segundo do Decreto $N^{\circ} 5.626$ (dez/2005), que regulamenta a Lei 10.436 (abril/2002).

5. Pretendo aprofundar este ponto a respeito dos horizontes sonoros que se abrem a partir dos usos que pessoas cegas fazem da audição, já esboçado em Von Der Weid (2014), em outro momento. 
6. Além do trabalho de Moraes (2007), é imprescindível mencionar, no cenário carioca, as pesquisas de Kastrup e Vergara (2013), Gonçalves (2009), Pozzana (2013) e Andrade (2016), com as quais entrei em contato de forma mais ou menos aproximada ao longo destes anos de pesquisa. Vale salientar que tais menções são direcionadas pela minha própria experiência de trabalho de campo e não por um levantamento exaustivo de pesquisas sobre a temática da arte na interface com a deficiência visual. Sobre o assunto, ver ainda Moraes e Kastrup (2010), Oliveira (2002) e Cunha (2004).

\section{Referências bibliográficas}

ANDRADE, Aretha de. 2016. O outro lado do mundo: encontros entre surdocegueira e expressões artísticas. Tese (Doutorado em Programa de Pós-graduação em Artes Cênicas). Universidade Federal do Rio de Janeiro.

BIRDWHISTELL, Ray L. 1990. Kinesics and Context: essays on body motion communication. Philadelphia: University of Pennsylvania press.

BRUNO, Marilda Moraes G. 2009. Avaliação educacional de alunos com baixa visão e múltipla deficiência na educação infantil. Dourados, MS: Editora UFGD.

CRAPANZANO, Vincent. 2005. "Horizontes Imaginativos e o aquém e além”. Revista de Antropologia, p. 363-384.

CUNHA, Malíria Flávia. 2004. “A expressão corporal e o deficiente visual”. Revista Benjamin Constant, Rio de Janeiro, ano 10, n. 28.

DINIZ, Débora; MEDEIROS, Marcelo \& SQUINCA, Flávia. 2007. "Reflexões sobre a versão em português da Classificação Internacional de Funcionalidade, Incapacidade e Saúde da Organização Mundial da Saúde”. Cadernos de Saúde Pública, v. 23, n. 10, p. 2507-2510.

ELIAS, Norbert. 1994. O processo civilizador: uma história dos costumes. Rio de Janeiro: Zahar.

FOUCAULT, Michel. 2013. Vigiar e punir: nascimento da prisão. Petrópolis: Vozes.

FREHSE, Fraya. 2009. “Usos da rua”. In: FORTUNA, Carlos; LEITE, Rogério Proença (orgs.). Plural cidade: léxicos e culturas urbanas. Coimbra: CES.

GARLAND-THOMSON, Rosemarie. 1997. Extraordinary bodies: figuring physical disability in American culture and literature. New York: Columbia University Press.

GIL, José. 2001. Movimento total: o corpo e a dança. Lisboa: Relógio D’Água.

GOFFMAN, Erving. 1996. A representação do eu na vida cotidiana. Petrópolis: Vozes.

GOFFMAN, Erving. 2011. Ritual de Interação. Petrópolis: Vozes.

GONÇALVES, Ana Lúcia Palma. 2009. Atos no Escuro: uma Perspectiva Sensorial. Dissertação (Mestrado em Teatro). Programa de Pós-Graduação em Teatro do Centro de Letras e Artes da Universidade Federal do Estado do Rio de Janeiro, Rio de Janeiro.

HAMMER, Gili. 2013. “'This is the anthropologist, and she is sighted': Ethnographic Research with Blind Women”. Disability Studies Quarterly, v. 33, n. 2, p. 1-23.

HULL, John. 2001. "Recognizing another world”. The National Journal for People with Disability, Melbourne, v. 3, n. 2, p. 23-26.

INGOLD, Tim. 2015. Estar vivo. Petrópolis: Vozes. 
JACKSON, Michael. 1989. Paths toward a clearing: radical empiricism and ethnographic inquiry. Indianapolis: Indiana University Press.

KASTRUP, Virgínia \& VERGARA, Luiz G. 2013. "Zona de risco dos encontros multissensoriais: anotações éticas e estéticas sobre acessibilidade e mediações”. Trama Interdisciplinar, v. 4, n. 1, p. 53-68.

KATZ, Helena. 2009. "Método e Técnica: faces complementares do aprendizado da dança”. In: SALDANHA, S. (org.). Angel Vianna: sistema, método ou técnica. Rio de Janeiro: FUNARTE. p. 26-32.

KATZ, Helena \& GREINER, Christiane. 2001. “Corpo e Processos de comunicação”. Fronteiras estudos midiáticos, v. 3, n. 2, p. 65-74.

LABAN, Rudolf. 1978. Domínio do movimento. São Paulo: Summus.

LE BRETON, David. 2011. Antropologia do corpo e modernidade. Petrópolis: Vozes.

LE BRETON, David. 2009. As paixões ordinárias: antropologia das emoções. Petrópolis: Vozes.

MALINOWSKI, Bronislaw. 1986. "Introdução: o assunto, o método e o objetivo desta investigação". In: MALINOWSKI, B. Coleção antropologia: Malinowski. São Paulo: Ática.

MAUSS, Marcel. 2003. “As técnicas do corpo”. In: Sociologia e Antropologia. São Paulo: Cosac \& Naify.

MERLEAU-PONTY, Maurice. 1971. Fenomenologia da Percepção. Rio de Janeiro: Freitas Bastos.

MOL, A.; STRUHKAMP, R. \& SWIERSTRA, T. 2009. "Dealing with in/dependence: doctoring in physical rehabilitation practice”. Science, Technology \& Human Values, v. 34, n. 1, p. 55-76.

MORAES, Marcia. 2007. "Modos de intervir com jovens deficientes visuais”. Revista Semestral da Associação Brasileira de Psicologia Escolar e Educacional (ABRAPEE), v. 11, n. 2, p. 311-322.

MORAES, Marcia; CARDOSO-MANSO, C. \& LIMA-MONTEIRO, A. P. 2009. "Afetar e ser afetado: corpo e cognição entre deficientes visuais”. Universitas Psychologica, Bogotá, v. 8, n. 3, p. 785-792.

MORAES, Marcia \& KASTRUP, Virgínia. 2010. Exercícios de ver e não ver. Rio de Janeiro: NAU.

MOREIRA, Adriana Belmonte. 2008. "Terapia Ocupacional: história crítica e abordagens territoriais / comunitárias”. Vita et Sanitas, Trindade/GO, v. 2, n. 2, p. 79-91.

MOSER, Ingunn. 2000. “Against normalisation: subverting norms of ability and disability”. Science as Culture, v. 9, n. 2, p. 201-240.

OLIVEIRA, João Vicente G. 2002. Do essencial invisível: arte e beleza entre os cegos. Rio de Janeiro: Renavan.

POZZANA, Laura. 2013. Movimento sensível e vital: uma oficina articulando a cegueira com o mundo. Tese (doutorado em Psicologia). Instituto de Psicologia, Programa de Pós-Graduação em Psicologia, Universidade Federal do Rio de Janeiro.

RABELO, Miriam, C. M. 2011. "Estudar a religião a partir do corpo: algumas questões teórico-metodológicas”. Caderno CRH, Salvador, v. 24, n. 61, p. 15-28.

REYNOLDS, Joel M. 2017. "Merleau-Ponty,World-Creating Blindness, and the Phenomenology of Non-Normate Bodies”. Chiasmi International: Trilingual Studies Concerning Merleau-Ponty's Thought, n. 19, p. 419-434.

RODRIGUES, Maria Rita C. 2014. Mosaico no tempo: uma inter-ação entre corpo, cegueira e baixa visão. Rio de Janeiro: Instituto Benjamin Constant. 
ROLNIK, Suely. 1993. "Pensamento, corpo e devir: uma perspectiva ético/estético/ política no trabalho acadêmico”. Cadernos de Subjetividade, v. 1, n. 2, p. 241-251.

SAUTCHUK, Carlos Emanuel \& DEBORTOLI, José Alfredo O. 2013. "Técnica, corpo e arte: aproximações entre antropologia e motricidade”. Licere, Belo Horizonte, v. 16, n. 2, p. 1-19.

SILVA, Rodrigo C. Dias. 2016. Gestos Exemplares: sobre alguns modos de apreensão gestual da exemplaridade. Tese (Doutorado em Sociologia e Antropologia). Universidade Federal do Rio de Janeiro.

TARDE, Gabriel. 2000. As leis da imitação. Porto: Rés.

VON DER WEID, Olivia. 2014. Visual é só um dos suportes do sonho: práticas e conhecimentos de vidas com cegueira. Tese (Doutorado em antropologia cultural). Rio de Janeiro: PPGSA/ UFRJ.

VON DER WEID, Olivia. 2017. "Provincializar a visão: esboços para uma abordagem metodológica”. Teoria e Cultura, v. 11, p. 131-144.

VYGOTSKY, Lev. S. 1997. Fundamentos de defectologia. In: VYGOTSKY, L. S. Obras escogidas. Madrid: Visor.

WINANCE, Myriam. 2007. "Being normally different? Changes to normalization processes: from alignment to work on the norm”. Disability \& Society, v. 22, n. 6, p. 625-638.

WINKIN, Yves. 1998. A nova comunicação: da teoria ao trabalho de campo. Campinas: Papirus. 
A "janela da expressão": reflexões sobre corpo, movimento e gesto nas relações entre visão e cegueira

Resumo: $O$ artigo considera os meios não discursivos que medeiam a relação entre expressividade e comunicação entre pessoas cegas e não cegas. Quais as implicações advindas de uma interação que se baseia na dupla condição de ver e não ser visto / não ver e ser visto? Qual o papel dos movimentos corporais nesta experiência comunicativa? A restrição social ao toque entre as pessoas traz implicações para a apreensão, por pessoas cegas, de uma linguagem comunicativa presente nos gestos, seja como forma de conhecimento cultural seja como recurso expressivo nas relações de interação. Abordo as consequências desse hiato a partir das possibilidades criativas que se abrem para o resgate e a construção desta linguagem corporal por intermédio da arte, a partir da participação, como parte do trabalho de campo, em oficinas de teatro com pessoas cegas e não cegas.

Palavras-chave: gesto, cegueira, arte, corpo, movimento.
The "window of expression": reflections about body, movement and gesture in the relations between vision and blindness

Abstract: The article considers the non-discursive means that mediate the relationship between expression and communication between blind and non-blind people. What are the implications of an interaction that is based on the double condition of seeing and not being seen / not seen and being seen? What is the role of the corporeal movements in this communicative experience? The social restriction of touch between people has implications for the apprehension, by blind people, of a communicative body language alive in gestures, either as a form of cultural knowledge or as an expressive resource in interaction relations. I discuss the consequences of this hiatus on the basis of the creative possibilities that opens up for the rescue and construction of this body language through art, with the participation, as part of fieldwork, in theater workshops with blind and non-blind persons.

Keywords: gesture, blindness, art, body, movement. 